\title{
Priority of Challenges for Activation of MyData Business: K-MyData Case
}

\author{
Jeong Kwan Park ${ }^{1}$, Soo Kyung Park ${ }^{2}$, and Bong Gyou Lee ${ }^{3 *}$ \\ ${ }^{1}$ Graduation School of Information, Yonsei University, Seoul, Republic of Korea \\ [e-mail: jkpark5331@yahoo.co.kr] \\ ${ }^{2}$ Graduation School of Information, Yonsei University, Seoul, Republic of Korea \\ [e-mail: sk.park@yonsei.ac.kr] \\ ${ }^{3}$ Graduation School of Information, Yonsei University, Seoul, Republic of Korea \\ [e-mail: bglee@yonsei.ac.kr] \\ ${ }^{*}$ Corresponding author: Bong Gyou Lee
}

Received April 25, 2021; revised July 14, 2021; revised August 17, 2021; revised September 12, 2021; accepted September 18, 2021; published October 31, 2021

\begin{abstract}
This paper identifies challenging factors that hinder the successful settlement of the MyData industry, which is drawing global attention, and it analyzes the priority of solutions. To this end, a mixed-methodology including analytic network process technique was borrowed stepby-step to identify variables, analyze them, and provide interpretations. From the first step, the study found that the market aspect was the most important for the success of the K-MyData business, and the release of interesting representative services was found to be the easiest way to inspire market growth. From the second step, as a socio-cultural issue, the lack of consensus on data provisioning was found to present a major obstacle. To achieve consensus, it is very important for business participants to gain the trust of consumers. From the third step, it was found that the scope of data collection and responsibility for accidents needs to be clarified. Government and business-related persons must observe the principles of MyData while tackling these obstacles. It is also necessary for the government to be sensitive to changes in the environment as a focal actor. Doing so will lead to data industry activation and will help guarantee of rights of data subjects in a balanced manner. Finally, it is notable that technical barriers now have the lowest priority. Although technology is important, MyData business must also overcome market, socio-cultural, and institutional challenges. The study selected Korea as its research target, but it is expected to provide useful insights to other countries that are planning MyData business similar to Korea.
\end{abstract}

Keywords: Analytic Network Process, Challenges, Mixed Method, MyData, Personal Data, Socio-technical System 


\section{Introduction}

MyData service, which allows individuals to decide what data to reveal about themselves without being overridden by companies or institutions that collect and store the data, has recently received much attention due to its novel concept. MyData allows personal data management to citizens. Although the meaning of this varies with each country, it is clear that the move was started to find the solutions to people's data-related concerns [1].

The core of MyData is that the individual has control and management over their personal data. For this reason, early research dealing with MyData or personal data has generated considerable interest in who the subject of data transactions or the owner of data from a legal or political-economic point of view must be. These studies, emphasizing "MyData Activism," asserted that the individual possessing the data should be the subject of the rights related to the data production [2] [3] [4]. Thus, as the right to data portability for the individual is emphasized, the subject for data production becomes the subject of ownership [5]; there have also been many discussions about data governance [6].

As such academic discussions progress, institutional preparations and social consensus are being formed for the MyData service. Further, in major countries, such as the United States, United Kingdom, and Japan, services similar to MyData have already begun to be introduced to the market. Hence, for the successful settlement of business, the expansion of academic debate from discourse to more practical research is required. In other words, there is a need to expand the business perspective to one of the pillars of the ecosystem, i.e., the perspective of operators who operate the MyData service while sympathizing with the principle of MyData. If the agency or operator leading the MyData business fails to succeed, the business may not be formed and it will be difficult to realize data activism.

The studies conducted from a business perspective are as follows. Representatively, some researchers have studied market changes from the perspective of the business use of personal data [7] [11]. In a case study, Huhtala et al. [7] found that the use of human-centric personal data as a resource may alter business models related to key activities, key resources, and value propositions. Kemppainen et al. [11] sent questionnaires to 27 personal-data-related operators from 12 countries and categorized revenue models according to transaction, service, connection, and membership fees. In addition, studies on the MyData business model, centering on services such as health insurance, have been conducted [12] [13]. These discussions have provided a foundation for understanding the changes in the market using MyData and contributed to explaining the characteristics of MyData business. However, these studies have certain limitations; they are exploratory studies that were conducted based on the potential of the MyData service. There is a shortage of research that explores difficulties from the perspective of operators participating in the MyData business and attempts to discover and analyze the insights of MyData. For the successful settlement of the MyData business, it is important to understand the actual experiences and needs of the people involved in the business. In particular, the discovery of success factors and barriers of using data to advance services remains a research gap [7]. Accordingly, this research aims to fill the gap from the perspective of MyData-related businesses, including the challenges that must be overcome to help the ecosystem work properly.

To this end, Korea's MyData services (K-MyData), which were received government permission in January 2021 and will be released in the market in December of the same year, were selected as a research target. Since Korea is promoting the K-MyData service with the aim of activating the data industry while guaranteeing data rights for subjects [8], it is a suitable object of research. 
The research questions of this study are as follows. First, from the perspective of the members of the MyData ecosystem, what are the challenges to the activation of the MyData industry and what are the priorities? Second, is there a difference in the perception of the challenges between MyData operators and its supporters? The first research question was designed to comprehensively examine the difficulties recognized by business operators participating in the MyData business. In addition, for the successful settlement of business, it is important to establish a phased strategy [9]. The second research question aids in classifying their characteristics in order to hear the voices of business operators in more detail. In general, operators are participants who directly carry out the MyData business, and supporters are participants who make profits by providing operators with their data or technology [10]. Therefore, the two groups are the core operators of the ecosystem, but their perceptions of the challenges may differ because they can be different in terms of the subjectivity of the business.

This study took a step-by-step approach to its mixed methodology. First, it identified obstacles to the activation of the K-MyData industry, for that purpose, a literature research was conducted. Specifically, existing research based on personal data and big data, which are the previous stages of MyData, were analyzed. The studies examining the obstacles to business in the context of personal data and big data were organized. In addition, distributed articles (government and industry reports, and news data) that discussed the challenges of MyData were collected and organized.

Then, through in-depth interviews, new empirical obstacles were discovered that were missed in the literature. Second, the analytic network process (ANP) technique was used to analyze the perception of players' obstacles. A second set of in-depth interviews was later conducted to provide a rich interpretation of the analysis results. As such, this research utilized a mixed methodology to solve the research questions in stages and to comprehensively interpret the found phenomena [14]. The results of this study are expected to illuminate the potential success of human-centric MyData in terms of business, and it will become a reference to worldwide governments and markets as they prepare for MyData or equivalent services.

\section{Literature Review}

\subsection{MyData Industry context in Korea}

The MyData effort provides a human-centric approach to personal data distribution. Presently, companies and institutions that manage customer data tend to enact ownership of the data as delegated by the customers who have data processing authority. Individuals are aware of some of these measures, but remain unaware of the details of data sharing, data transference, and data use [1]. MyData intends to change this paradigm. The basic principles are summarized as follows [15] [16]. First, there is a shift from formal to actionable rights. This underscores that an individual's right to their data should not exist only in a formal manner. Second, the authority is now granted to the individual to make decisions about the handling of data possessed by organizations. In other words, the individual is the subject of actual data protection and utilization. Substantial authority is thus granted to the individual. Third, the data industry must move from closed to open ecosystems. This is intended to create balance, fairness, diversity, and competition in the data economy by enabling freely flowing data.

Several obstacles exist, however, between these objectives and the reality of achievement. The MyData business model is divided into two paradigms: government- and market-led models. First, the government-led models include the United Kingdom's Midata and the United States' Blue Button and Green Button systems, which are represented by smart 
disclosure [17] [18]. They are led by the government with the purpose of democratizing data. Japan's information trust banking system is included in the list of government-led models. Second, market-led models include mint.com, Yodlee, Credit Karma, and Digi.me in the United States and Ping-an Insurance in China (a model in which the market performs autonomously).

In August 2020, Korea introduced a government-led K-MyData business initiative by revising the Credit Information Act to boost the data industry. Fintech firms, including the Bank Salad and Toss in Korea, were used as models of MyData market autonomy. The government is pursuing both the right of self-determination of personal information and the goal of activating the data industry simultaneously by launching K-MyData. The characteristics of K-MyData are as follows: First, only a limited number can enter the market through a licensing system. In January 2021, 28 businesses were licensed mainly in the financial industry. Although K-MyData is being attempted in medical, public administration, telecommunications, real estate, and transportation industries, others are operating in the form of pilot services. Third, the specific role of K-MyData operators in the financial industry is specified by law. A mandatory data transmission system has been introduced; consequently, if requested by the individual owner of personal data, financial institutions, telecommunication companies, and E-commerce businesses are required to send credit information to the KMyData business operator (Credit Information Act, article 33-2 (3)) [8]. At this time, businesses should use only standard application program interfaces (APIs). Fourth, MyData operators may sell the information to third parties only after they pseudonymize the data, which refers to "unidentifiable personal information" that cannot identify a particular individual without additional information [8]. In summary, Korea is starting a government-led $\mathrm{K}-\mathrm{MyData}$ business centered on the financial sector.

Therefore, this study aims to provide implications for business settlements by identifying the challenges' factors of MyData activation and drawing the priority of solutions, focusing on the financial sector where K-MyData services are active.

\subsection{Challenges to the activation of MyData}

This study examined multiple studies to identify obstacles related to under-researched MyData activation scenarios. Since the concept of MyData has begun to garner interest relatively recently, studies dealing with the challenge for the activation of MyData are rare. Hence, this study analyzed research related to big data and personal data, which are concepts that precede MyData, and selected the discussions that are relevant to MyData. The discussions were then classified according to the socio-technical system (STS) perspective. A STS perspective recognizes the importance of human beings and society in the development of technology and assumes a view that considers not only technology but also quality of life and the socio-cultural environment [19] [20] [21].

Regarding technology, the first barrier is infrastructure readiness [22]. Big data analysis requires large investments in terms of hardware, because most existing technologies do not meet the requirements of big data analysis. Second, the complexity and inherent disorderliness of big data is also considered an obstacle [23]. Digital data is often stored in different formats with unstructured databases and various types of text files. Worldwide data is growing at a tremendous rate daily; thus, it is difficult to adequately handle data from different sources and formats [24]. Third, the lack of human resources for big data handling is a major obstacle, which leads to errors [25] [26].

Social barriers are also a big problem. First, privacy protection is a huge obstacle [23] [24], because big data mostly comprises personally identifiable information [28]. This obstacle 
prevents organizations from fully capitalizing on big data analysis [29]. Second, the culture of an organization tends to also acts as an obstacle to the adoption of big data, especially if they do not understand it or recognize its value [30] [31].

Although the discussion of big data barriers has some explanatory power, it is still necessary to review new factors related to the K-MyData context owing to differences. The value chain of a typical big data firm may consist of data acquisition, data analytics, data curation, data storage, and data usage [32]. However, in the case of K-MyData, as shown in Fig. 1, the steps become more complicated. Most big data flows only between individuals and banks, which use collection and storage analysis institutions. However, with K-MyData, there is also consumption and use by MyData operators and marketing companies. Accordingly, additional consideration of this relationship is needed when identifying the barriers.

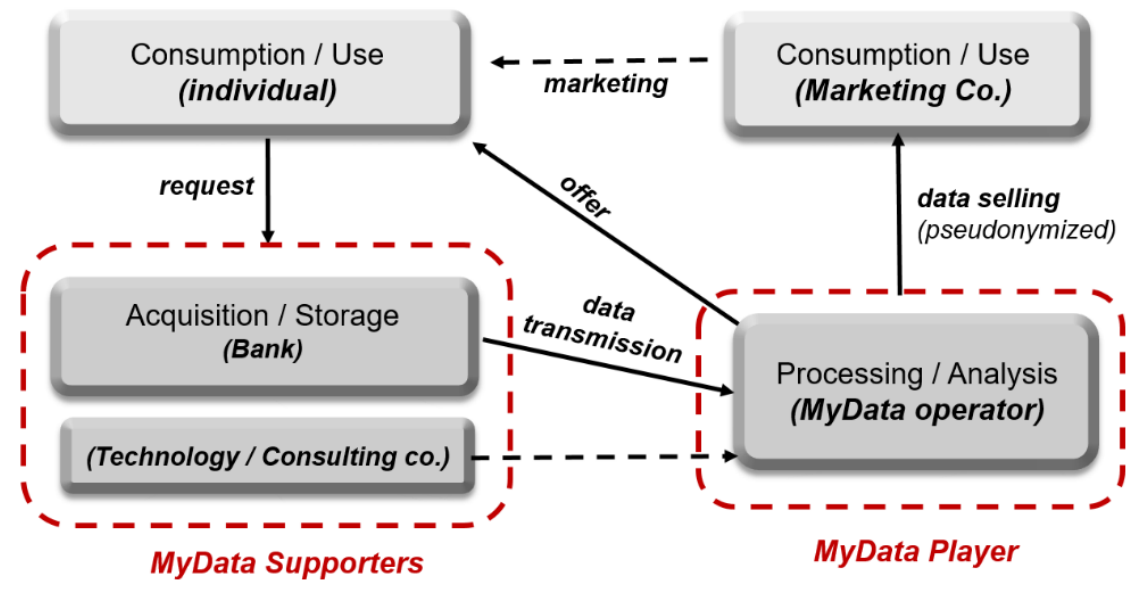

Fig. 1. K-MyData Value Chain

Considering these characteristics, the challenges are as follows: In terms of technology, first, the lack of interoperability is an important obstacle [33] [34] because MyData should be able to send and receive data from its existing collection, storage institutions, and MyData operators using API technology. Second, a data analyst who can analyze MyData may be a critical obstacle in analyzing personal data [35] [36]. This is because it cannot be selected as their MyData service provider unless it provides suitable analytics services to individuals.

Regarding the social aspects, other obstacles exist. First, there is a lack of consensus on the provision and utilization of data [36]. If there is a lack of incentives that exceed the risk for individuals, social and cultural consensus on the provision and utilization may not be formed. Second, the lack of trust in the new MyData business is a big challenge [33]. There is no guarantee that MyData-related service providers will act lawfully and in good faith. Based on the understanding of the challenges demonstrated in the existing literature, this study examined the obstacles to activating MyData. In-depth interviews were conducted to discover new variables that were not revealed in the literature, and detailed procedures and methods are described in Section 3.

\section{Methodology}

This study used a sequentially phased mixed methodology approach to answer the given research questions for the following reasons. First, it was identified that there is a lack of 
existing discussions about the obstacles to the success of MyData initiatives. Hence, by combining the results of the literature review with a qualitative method, we discovered new challenge factors related to people's experiences. In the literature review, research dealing with similar issues was collected and analyzed. This included not only MyData research, but also research on preceding concepts. In addition, interviews with twenty-one experts were conducted to discover new factors that were not observed in the literature. The information gathered from these interviews served as a basis for establishing a model for this research. Second, a survey was conducted with industry experts. This is because it is important to establish a phased strategy for the successful settlement of business [9]. The factors urgently needed to solve the problem were selected by applying the method of ANP. Finally, an indepth interview was conducted for the interpretation of the research results. This study collected qualitative data first, followed by quantitative data [37]. This phased approach offsets problems that would otherwise arise using a single methodology [23] [30]. Additionally, a phased resolution of research questions and the results of the research will more harmoniously contribute to scientific and practical applications [14] [38] [39].

2.

The detailed research processes and methodologies for this study are as presented in Fig.

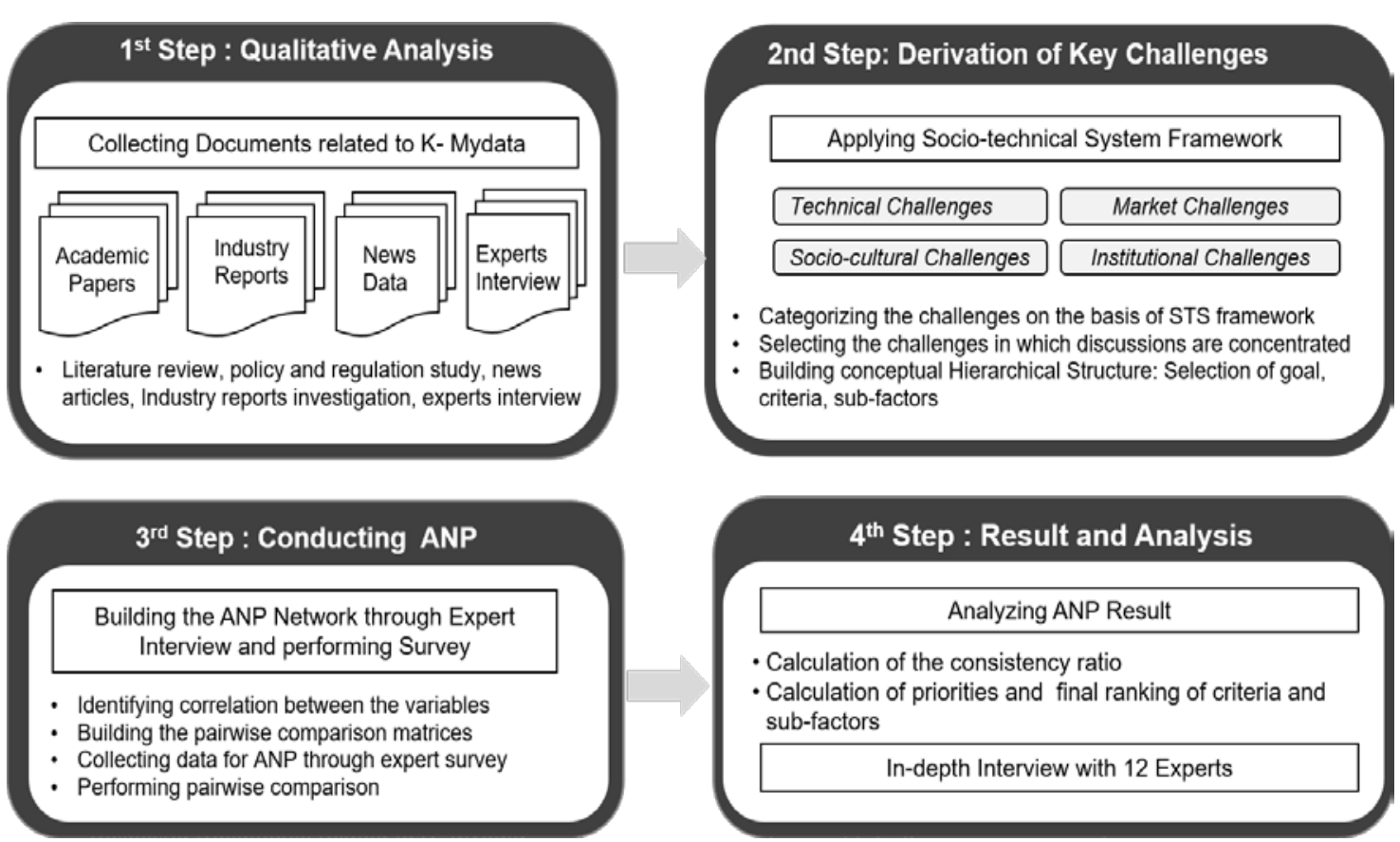

Fig. 2. Procedures and Methodology for Research

\subsection{Qualitative Analysis}

First, the researchers identified suitable variables related to the MyData challenge factors by researching the extant literature, as discussed in Section 2.2. Moreover, the researchers scrutinized specialized government reports and those of consulting industries using keywords, such as "MyData," "big data," "personal data," "barrier," "challenge," "task," and further reviewed news analyses to determine whether there were any important discussions missed by researchers. Then, in-depth interviews were conducted with 21 experts related to MyData to discover the empirical variables. 
The in-depth interview methodology is designed to obtain deep insights from interviewees; these insights become the research data [40]. The interviewees of this study included scholars of the field, lawyers, civic groups, and industry experts. Determinations of interviewee suitability was made based upon the number of years of work in the field so that there would be some guarantee that subjects would have insight into the practical obstacles related to MyData implementation. Their average working experience was 18.4 years (Appendix 1). The interviews took place between July and October 2020, and each expert was interviewed for about an hour.

\subsection{Derivation of Key Challenges}

The variables discovered through literature research and in-depth interviews were largely based on the STS framework (Appendix 2) [41] [42]. The process of deriving the key challenges of this research is as follows: First, the STS framework is applied, and the key challenges plaguing the current MyData business model are categorized into four criteria. In addition, the results of the literature review and the information from the expert interviews are placed in sub-factors under four criteria. The first criterion is "Technical Challenges." The literature review showed that many papers have already addressed the technical challenges. Eight sub-factors were derived by arranging the concepts discussed in each document based on the similarity between them. The second criterion is "Market Challenges." Again, eight sub-factors were derived. The third criterion is "Socio-cultural Challenges." Contrary to other businesses, the "person" can be regarded as the point of origin of the MyData business model since the "person" has data sovereignty and is an essential part of the business This criterion has been organized into five sub-factors that are socio-cultural reasons that people recognize as the cause for their hesitation in adopting MyData. The fourth criterion is "Institutional Challenges.” These comprise hurdles present in the laws, systems, and regulatory institutions that were established for the rapid activation of MyData projects. Six sub-factors were derived. These sub-factors, unlike those of the other key challenges, are ones that were mainly observed in newspaper articles or gleaned through interviews. This is due to the scarcity of papers on K-MyData because it is yet to be implemented.

Following the categorization of the sub-factors of the key challenge, the researchers performed the final variable selection for this study. The key challenges referred to in Appendix 2 represent most of the current challenges the MyData business is facing. Hence, the final screening of these challenges to determine the variable for this study is necessitated. In this study, a hierarchical structure should be established because the ANP technique is applied based on the pairwise comparison between factors. Accordingly, the structure must be configured so that pairwise compliance performances are achievable [9]. As a result, four subfactors are assigned to each of the four criteria. This implies that four kinds of challenges that are central to the current debate are selected, with each representing a higher level of complexity. Initially, the variables were selected based on how frequently they appeared in the literature and the interviews. Subsequently, the researchers attempted to determine factors that are important in understanding the characteristics of the MyData business, although there are few mentions of them in the existing literature. These factors were included with existing ones and newly named. In conclusion, four criteria and sixteen sub-factors for the execution of the ANP technique were derived. (Table 1). 
Table 1. Key challenges to activating K-MyData

\begin{tabular}{|c|c|c|}
\hline $\begin{array}{c}\text { Key challenges } \\
\text { (criteria and sub-factors) }\end{array}$ & Definition & References \\
\hline \multicolumn{3}{|l|}{ 1. Technical challenges } \\
\hline $\begin{array}{l}\text { 1.1. Insufficient Standardization } \\
\text { of Data Transmission and } \\
\text { Receipt (API) }\end{array}$ & $\begin{array}{l}\text { - Insufficient technology for developing the } \\
\text { API system for data transmission and } \\
\text { reception }\end{array}$ & • [10] [33] [34] [48] \\
\hline $\begin{array}{l}\text { 1.2. Insufficient Data Storage } \\
\text { Management Technology }\end{array}$ & $\begin{array}{l}\text { - Lack of technology (such as cloud and } \\
\text { network separation) to safely store and } \\
\text { manage transmitted personal data }\end{array}$ & • [23] [33] [49] [50] \\
\hline $\begin{array}{l}\text { 1.3 Insufficient Data Quality } \\
\text { Management Technology }\end{array}$ & $\begin{array}{l}\text { - Lack of technology to control the quality of } \\
\text { data so that K-MyData distribution can be } \\
\text { maintained steadily }\end{array}$ & $\begin{array}{l}\text { - }[41][51][53] \\
\text { - Interviewee } 10\end{array}$ \\
\hline $\begin{array}{l}\text { 1.4 Insufficient Data Security } \\
\text { Technology }\end{array}$ & $\begin{array}{l}\text { - Lack of security technology to protect data } \\
\text { safely }\end{array}$ & - [23] [31] [41] [54] \\
\hline \multicolumn{3}{|l|}{ 2. Market Challenges } \\
\hline $\begin{array}{l}2.1 \text { Lack of Specialists (Data } \\
\text { Analysts) }\end{array}$ & $\begin{array}{l}\text { - Lack of professionals who can converge and } \\
\text { analyze data between different industries }\end{array}$ & • [23] [33] [35] [54] \\
\hline $\begin{array}{l}\text { 2.2 Lack of Clear-cut Profit } \\
\text { Models }\end{array}$ & $\begin{array}{l}\text { - No clear-cut profit model to exceed risk to } \\
\text { market participants }\end{array}$ & $\begin{aligned} \cdot & {[33][34][41] } \\
& {[52][55] }\end{aligned}$ \\
\hline $\begin{array}{l}\text { 2.3 Lack of Representative } \\
\text { Innovative Services }\end{array}$ & $\begin{array}{l}\text { - Necessity to create representative innovative } \\
\text { services that can create consumer demand }\end{array}$ & $\begin{array}{l}\text { - }[35][47][54] \\
\text { - Interviewee } 2\end{array}$ \\
\hline $\begin{array}{c}\text { 2.4 Lack of Expansion of Co- } \\
\text { work Players in Market }\end{array}$ & $\begin{array}{l}\text { - Shortage of players capable of co-working } \\
\text { for each phase (element) of the ecosystem }\end{array}$ & - Interviewee 12 \\
\hline \multicolumn{3}{|l|}{ 3. Socio-cultural Challenges } \\
\hline $\begin{array}{l}\text { 3.1 Lack of Consensus on the } \\
\text { Provision and Utilization of } \\
\text { Personal Data }\end{array}$ & $\begin{array}{l}\text { - Lack of social and cultural consensus on } \\
\text { delivery and utilization due to lack of } \\
\text { incentives that go beyond the risk to } \\
\text { individuals }\end{array}$ & • [23] [31] [33] \\
\hline $\begin{array}{l}\text { 3.2 Lack of Trust in Business } \\
\text { Entities }\end{array}$ & $\begin{array}{l}\text { - Lack of trust that K-MyData-related service } \\
\text { providers will act lawfully and in good faith } \\
\text { with their personal data }\end{array}$ & - [34] [41] \\
\hline 3.3 Fear of Privacy Infringement & $\begin{array}{l}\text { - Fear of privacy infringement or personal } \\
\text { information leakage of individuals in the } \\
\text { course of providing services }\end{array}$ & - [23] [41] \\
\hline 3.4 Low Awareness of Service & $\begin{array}{l}\text { - Individual's low awareness and lack of } \\
\text { understanding of K-MyData services }\end{array}$ & - Interviewee 3 \\
\hline \multicolumn{3}{|l|}{ 4. Institutional Challenges } \\
\hline $\begin{array}{l}\text { 4.1 Insufficient Improvement of } \\
\text { Liability-related Acts }\end{array}$ & $\begin{array}{l}\text { - In the event of an accident such as } \\
\text { divulgence of personal information, the level } \\
\text { of punishment tends to be excessive for some } \\
\text { business operators; thus, it is necessary to } \\
\text { improve related laws and regulations }\end{array}$ & $\begin{array}{l}\text { - [57] } \\
\text { - Interviewee } 4\end{array}$ \\
\hline $\begin{array}{l}\text { 4.2 No Clear Criteria for Data } \\
\text { Collection Scope }\end{array}$ & $\begin{array}{l}\text { - No clear standard for the scope of data that } \\
\text { can be collected by K-MyData (details of } \\
\text { transactions and the kinds of data other than } \\
\text { the scope that can be collected by API) }\end{array}$ & $\begin{array}{l}\text { - }[56][57] \\
\text { - Interviewee } 2\end{array}$ \\
\hline $\begin{array}{l}\text { 4.3 No Clear Criteria for Data } \\
\text { Ownership }\end{array}$ & $\begin{array}{l}\text { - The need to establish a clear standard for the } \\
\text { ownership of data generated in the course of } \\
\text { collection and to establish a system thereof }\end{array}$ & $\begin{array}{l}\text { - }[58] \\
\text { - Interviewee } 4\end{array}$ \\
\hline
\end{tabular}




\begin{tabular}{|c|c|c|}
\hline $\begin{array}{l}\text { 4.4 No Clear Leading Actor - the } \\
\text { Focal Actor among } \\
\text { Governments }\end{array}$ & $\begin{array}{l}\text { - No focal actor in the government; } \\
\text { government ministries related to MyData are } \\
\text { dispersed to the Financial Services } \\
\text { Commission, the Personal Information } \\
\text { Protection Commission, and the Ministry of } \\
\text { Science and ICT among others and cannot be } \\
\text { managed and promoted in an integrated } \\
\text { manner }\end{array}$ & $\begin{array}{l}\text { - }[59] \\
\text { - Interviewee } 12\end{array}$ \\
\hline
\end{tabular}

\subsection{Collecting Data and Conducting ANP Survey}

The ANP method was used to determine the priority of obstacles to activating MyData. The ANP is a network analytic, multi-criteria decision-making technique [9]. There is a difference in the importance of factors affecting the activation of MyData, and there is a relationship of impact among them. Therefore, the authors judged that the application of the ANP technique to network theory was appropriate for this study.

The ANP analysis procedure is as follows. The first step is to determine the correlation among variables [43]. In consideration of the fact that variables have interactivity and feedback relationships, the ANP research model has a network structure. A group of three industry experts and two professors identified the correlation between ANP variables with consensus (Appendix 3). Based on the results of the analysis of the association among variables, the ANP model and the questionnaire were composed. Second, the authors surveyed 34 industry experts on ANP analysis. The survey subjects performed a pairwise comparison on the KMyData challenges on a scale of one to nine [9] [44]. The analysis of the consistency index found that eight respondents were lacking in the consistency of their responses; hence, a total of 26 people were selected for the final analysis (see Table 2). The average of their consistency was 0.14. Subjects were divided into two groups (see Table 3 and Fig. 1). The first group included people who ran K-MyData operations. They were financial business operators with banks, credit-card firms, and newly entered FinTechs that had obtained K-MyData service permissions. Second were the supporters of K-MyData business, comprising consultants and telecom and e-commerce companies that are required to support K-MyData. Participants were identified using a snowball sampling method and based on the specific duties and work experience within their respective companies, they were verified and surveyed. The ANP survey was conducted between February and March 2021. Each survey was started following a thorough explanation of the ANP technique.

Table 2. Survey Subjects Overview

\begin{tabular}{|c|c|c|c|}
\hline Field & Specialized Field & Number of Respondents & Average Work Period \\
\hline \multirow{2}{*}{$\begin{array}{c}\text { Group 1: } \\
\text { K-MyData } \\
\begin{array}{c}\text { Operator } \\
(\mathrm{n}=14)\end{array}\end{array}$} & Bank & 3 & 14 years \\
\cline { 2 - 4 } & Card & 4 & 12.5 years \\
\cline { 2 - 4 } & Insurance & 1 & 16 years \\
\hline $\begin{array}{c}\text { Group 2: } \\
\text { K-MyData } \\
\text { Supporter } \\
(\mathrm{n}=12)\end{array}$ & Fintech & 6 & 15 years \\
\cline { 2 - 4 } & Mandatory Data Transmission & 7 & 20.2 years \\
\hline \multicolumn{2}{c}{ Total } & 26 & 16.1 years \\
\hline
\end{tabular}




\subsection{Survey Results and In-depth Interviews}

Based on the results of the 26 ANP responses, priorities were calculated, and the final ranking of criteria and sub-criteria was conducted [44]. Then, to interpret the ANP, in-depth interviews were scheduled and conducted. According to Bryman [40], the in-depth interview obtains deep insight from the interviewee and can be referred to as the data itself. The in-depth interviews consisted of 12 people who participated in the original survey, particularly those who had the longer careers in the data field and had experienced MyData pilot projects of the Ministry of Science and ICT in 2017 (Table 3).

Table 3. In-depth Interviews for Interpreting ANP Results

\begin{tabular}{|c|c|c|c|}
\hline Field & Code & Specialized Field & Work Period \\
\hline \multirow{3}{*}{$\begin{array}{c}\text { Group 1: } \\
\text { K-MyData } \\
\begin{array}{c}\text { Operator } \\
(\mathrm{n}=6)\end{array}\end{array}$} & $\mathrm{A}$ & Bank & 22 years \\
\cline { 2 - 4 } & $\mathrm{B}$ & Bank & 10 years \\
\cline { 2 - 4 } & $\mathrm{C}$ & Card & 20 years \\
\cline { 2 - 4 } & $\mathrm{D}$ & Card & 20 years \\
\cline { 2 - 4 } & $\mathrm{E}$ & Fintech & 22 years \\
\hline \multirow{3}{*}{$\begin{array}{c}\text { Group 2: } \\
\text { K-MyData } \\
\begin{array}{c}\text { Supporter } \\
\text { (n=6) }\end{array}\end{array}$} & $\mathrm{G}$ & Fintech & 25 years \\
\cline { 2 - 4 } & $\mathrm{H}$ & Technology and Service Consulting & 25 years \\
\cline { 2 - 4 } & $\mathrm{I}$ & Technology and Service Consulting & 23 years \\
\cline { 2 - 4 } & $\mathrm{J}$ & E-commerce & 20 years \\
\cline { 2 - 4 } & $\mathrm{L}$ & E-commerce & 21 years \\
\hline
\end{tabular}

\section{Results}

From the STS perspective, the ANP model of this study was categorized according to aspects of technology, market, socio-culture, and institution, and each category was divided into subcategories. This research model was defined through a cross-factor correlation review, and a research model (Fig. 3) was constructed.

\section{Challenges for Activation of K-MyData}

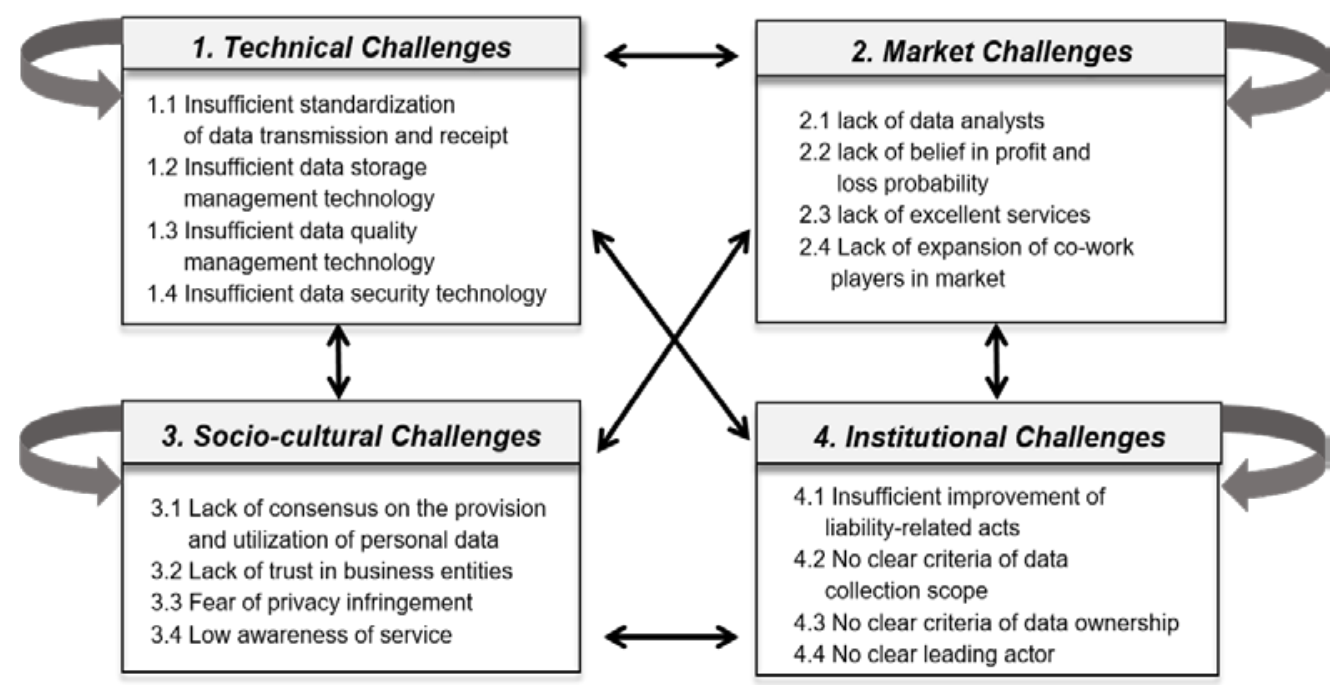

Fig. 3. Actor Network Model 


\subsection{Results of the Overall Analysis}

Table 4 presents the analysis of 26 respondents in total. According to the results of the overall priority, the importance of top factors was ordered by market, system, socio-culture, and technology. Alongside the ANP analysis results, the following activities (Table 4) were included in the results of the second set of in-depth interviews on the results of the ANP.

Table 4. Priority of Challenges to MyData Activation - Overall Results

\begin{tabular}{|c|c|c|c|c|}
\hline Main Criteria & Sub-factors & Weight & Eigenvector & Rank \\
\hline \multirow{4}{*}{$\begin{array}{c}\text { Technical } \\
\text { Challenges } \\
(0.0551)\end{array}$} & $\begin{array}{l}\text { 1.1 Insufficient Standardization of } \\
\text { Data Transmission and Receipt (API) }\end{array}$ & 0.0820 & 0.0045 & 16 \\
\hline & 1.2 Insufficient Data Storage Management Technology & 0.1556 & 0.0086 & 15 \\
\hline & 1.3 Insufficient Data Quality Management Technology & 0.4001 & 0.0221 & 12 \\
\hline & 1.4 Insufficient Security Technology & 0.3624 & 0.0200 & 13 \\
\hline \multirow{4}{*}{$\begin{array}{c}\text { Market } \\
\text { Challenges } \\
(0.4337)\end{array}$} & 2.1 Lack of Specialists (Data Analysts) & 0.1063 & 0.0461 & 8 \\
\hline & 2.2 Lack of Clear-cut Profit Models & 0.2669 & 0.1158 & 3 \\
\hline & 2.3 Lack of Representative Innovative Services & 0.5207 & 0.2258 & 1 \\
\hline & 2.4 Lack of Expansion of Co-work Players in Market & 0.1061 & 0.0460 & 9 \\
\hline \multirow{4}{*}{$\begin{array}{c}\text { Socio-cultural } \\
\text { Challenges } \\
(0.2422)\end{array}$} & $\begin{array}{l}\text { 3.1 Lack of Consensus on the Provision and Utilization } \\
\text { of Personal Data }\end{array}$ & 0.3982 & 0.0964 & 4 \\
\hline & 3.2 Lack of Trust in Business Entities & 0.2519 & 0.0610 & 6 \\
\hline & 3.3 Fear of Privacy Infringement & 0.1289 & 0.0312 & 11 \\
\hline & 3.4 Low Awareness of Service & 0.2210 & 0.0535 & 7 \\
\hline \multirow{4}{*}{$\begin{array}{c}\text { Institutional } \\
\text { Challenges } \\
(0.2689)\end{array}$} & 4.1 Insufficient Improvement of Liability-related Acts & 0.2758 & 0.0742 & 5 \\
\hline & 4.2 No Clear Criteria of Data Collection Scope & 0.5109 & 0.1374 & 2 \\
\hline & 4.3 No Clear Criteria of Data Ownership & 0.0513 & 0.0138 & 14 \\
\hline & $\begin{array}{l}\text { 4.4 No Clear Leading Actor - the Focal Actor among } \\
\text { Governments }\end{array}$ & 0.1620 & 0.0436 & 10 \\
\hline
\end{tabular}

According to the results, members of the K-MyData industry tended to believe that the market factor is the biggest challenge to its activation. The following institutional challenges were also identified as factors for market activation, and the most important consideration for $\mathrm{K}-\mathrm{MyData}$ businesses was confirmed as securing marketability. After comparing the subfactors of market challenge, securing excellent services and a belief in the possibility of profit and loss were ranked high. This suggests that there are still no representative innovative services that can generate demand for K-MyData businesses. Additionally, the results suggest that there is no clear monetization model for K-MyData that would offset risk. Regarding the institutional challenge, the ambiguity of scope criteria in data collection was cited as the biggest. This reflects the fact that API data collection is limited. Furthermore, the scope of the transaction information of e-commerce operators is controversial. Specifically, it was interpreted to be a result of the concern that when the K-MyData project is implemented, only data through the API could be collected, which would reduce the amount of information collection compared with the screen-scraping method that is currently freely used (Interviewee $G)$. The lack of social consensus on the provision and use of data is cited as the biggest obstacle 
to socio-cultural fulfillment. Additionally, in the order of trust in K-MyData operators, obstacles of low awareness of services and concerns about invasion of privacy were identified. Finally, data quality management technology was the most important obstacle to technical fulfillment. Hence, there is need for technology that supports high-quality managed data.

To compare only the sub-factors, among the 16 , barriers such as securing representative (excellent) innovative services, establishing standard ranges of data collection, the belief in the possibility of profit and loss, and securing consensus on data provision were the most frequently cited.

\subsection{Comparison by Group}

The analysis results by groups are as follows. The first group contains the K-MyData industry employees who directly conducted K-MyData business activities (Group 1: 14 members doing K-MyData business at banks, credit-card companies, insurance companies, and FinTechs). The second group contains MyData Supporters (Group 2: 12 members of companies that transmit data to K-MyData operators or support technology and consulting). The analysis results for each group are shown in Table 5 and Table 6.

The results of the above STS categories are discussed next. The results of the analysis of Group 1 showed similar results to those of most respondents. In contrast, Group 2 demonstrated the opinion that the market ranked the highest, followed by socio-culture, institution, and technology. This differences can be interpreted as follows. Interviewee $H$, who was involved in the MyData pilot service of the Ministry of Science and ICT, interpreted that the supporters' group "considers it more important to ultimately form a socio-cultural climate than an institutional one right away."

Differences in the sub-factors between the groups were also observed. Although there is no doubt that securing excellent services was the most important for both groups, Group 1 demonstrated that the next priority should be overcoming the ambiguous parts of the data collection criteria. Group 2 placed this item fourth in their priority. Additionally, Group 1 demonstrated with respect to data incidents that improvements to the unclear legal system comprised the fourth most important item. Group 2 ranked this issue seventh in importance. Additionally, Group 1 considered the lack of a focal actor among governments as the seventh obstacle, whereas Group 2 evaluated it somewhat lower. Experts interpreted the differences in the analysis results of the sub-factors as follows. Group 1, which directly conducted KMyData business, identified more realistic areas of improvement (e.g., government institutions focal actors). The supporters considered improvements to socio-cultural factors as being more important from a less-involved perspective. In other words, MyData operators interpreted the burden of profiting from MyData business and individual performance as more important (Interviewees A, B, D). Supporters (Group 2) considered the overall solution, wherein the fully forming the market was more important because it would serve as a technology and consulting provider and a data deliverer (Interviewees $J, K$ ). Nevertheless, both groups had the same view that the success of K-MyData was the critical factor of market success. In particular, there was a consensus that securing excellent services was the biggest obstacle. Hence, Interviewee I stated that "the market will open eventually if innovative services are available." Both groups found that data ownership was not a major obstacle, and it was 14th in the list of priorities. This is a different result from what was mentioned by civic groups and academicians as important during the news analysis and the first set of in-depth interviews. However, it is more desirable to interpret the results as "I recognized that data ownership is not urgent (compared to other tasks)," rather than the interpretation that "data ownership is not important" (Interviewee B). 
Table 5. Priority of Challenges to MyData Activation - Group 1: K-MyData Operators

\begin{tabular}{|c|c|c|c|c|}
\hline Main Criteria & Sub-factors & Weight & Eigenvector & Rank \\
\hline \multirow{4}{*}{$\begin{array}{c}\text { Technical } \\
\text { Challenges } \\
(0.0639)\end{array}$} & $\begin{array}{l}\text { 1.1 Insufficient Standardization of } \\
\text { Data Transmission and Receipt (API) }\end{array}$ & 0.0951 & 0.0061 & 16 \\
\hline & 1.2 Insufficient Data Storage Management Technology & 0.1233 & 0.0079 & 15 \\
\hline & 1.3 Insufficient Data Quality Management Technology & 0.4379 & 0.0280 & 12 \\
\hline & 1.4 Insufficient Security Technologies & 0.3438 & 0.0220 & 13 \\
\hline \multirow{4}{*}{$\begin{array}{c}\text { Market } \\
\text { Challenges } \\
(0.3947)\end{array}$} & 2.1 Lack of Specialists (Data Analysts) & 0.1179 & 0.0465 & 9 \\
\hline & 2.2 Lack of Clear-cut Profit Models & 0.2586 & 0.1021 & 3 \\
\hline & 2.3 Lack of Representative Innovative Services & 0.5172 & 0.2041 & 1 \\
\hline & 2.4 Lack of Expansion of Co-work Players in Market & 0.1064 & 0.0420 & 10 \\
\hline \multirow{4}{*}{$\begin{array}{c}\text { Socio-cultural } \\
\text { Challenges } \\
(0.2161)\end{array}$} & $\begin{array}{l}\text { 3.1 Lack of Consensus on the Provision and Utilization } \\
\text { of Personal Fata }\end{array}$ & 0.3695 & 0.0798 & 5 \\
\hline & 3.2 Lack of Trust in Business Entities & 0.2764 & 0.0597 & 6 \\
\hline & 3.3 Fear of Privacy Infringement & 0.1326 & 0.0287 & 11 \\
\hline & 3.4 Low Awareness of Service & 0.2214 & 0.0478 & 8 \\
\hline \multirow{4}{*}{$\begin{array}{c}\text { Institutional } \\
\text { Challenges } \\
(0.3253)\end{array}$} & 4.1 Insufficient Improvement of Liability-related Acts & 0.2810 & 0.0914 & 4 \\
\hline & 4.2 No Clear Criteria of Data Collection Scope & 0.5012 & 0.1630 & 2 \\
\hline & 4.3 No Clear Criteria of Data Ownership & 0.0513 & 0.0167 & 14 \\
\hline & $\begin{array}{l}4.4 \text { No Clear Leading Actor - the Focal Actor among } \\
\text { Governments }\end{array}$ & 0.1665 & 0.0542 & 7 \\
\hline
\end{tabular}

Table 6. Priority of Challenges to MyData Activation - Group 2: K-MyData Supporters

\begin{tabular}{|c|c|c|c|c|}
\hline Main Criteria & Sub-factors & Weight & Eigenvector & Rank \\
\hline \multirow{4}{*}{$\begin{array}{c}\text { Technical } \\
\text { Challenges } \\
(0.0438)\end{array}$} & $\begin{array}{l}\text { 1.1 Insufficient Standardization of } \\
\text { Data Transmission and Receipt (API) }\end{array}$ & 0.0655 & 0.0029 & 16 \\
\hline & 1.2 Insufficient Data Storage Management Technology & 0.2021 & 0.0089 & 15 \\
\hline & 1.3 Insufficient Data Quality Management Technology & 0.3630 & 0.0159 & 13 \\
\hline & 1.4 Insufficient Security Technology & 0.3694 & 0.0162 & 12 \\
\hline \multirow{4}{*}{$\begin{array}{c}\text { Market } \\
\text { Challenges } \\
(0.4916)\end{array}$} & 2.1 Lack of Specialists (Data Analysts) & 0.0937 & 0.0460 & 9 \\
\hline & 2.2 Lack of Clear-cut Profit Models & 0.2796 & 0.1375 & 2 \\
\hline & 2.3 Lack of Representative Innovative Services & 0.5283 & 0.2597 & 1 \\
\hline & 2.4 Lack of Expansion of Co-work Players in Market & 0.0985 & 0.0484 & 8 \\
\hline \multirow{4}{*}{$\begin{array}{c}\text { Socio-cultural } \\
\text { Challenges } \\
(0.2604)\end{array}$} & $\begin{array}{l}\text { 3.1 Lack of Consensus on the Provision and Utilization } \\
\text { of Personal Data }\end{array}$ & 0.4258 & 0.1109 & 3 \\
\hline & 3.2 Lack of Trust in Business Entities & 0.2315 & 0.0603 & 5 \\
\hline & 3.3 Fear of Privacy Infringement & 0.1211 & 0.0315 & 11 \\
\hline & 3.4 Low Awareness of Service & 0.2216 & 0.0577 & 6 \\
\hline
\end{tabular}




\begin{tabular}{|c|l|l|l|c|} 
& 4.1 Insufficient Improvement of Liability-related Acts & 0.2649 & 0.0541 & 7 \\
\cline { 2 - 5 } $\begin{array}{c}\text { Institutional } \\
\text { Challenges } \\
(0.2042)\end{array}$ & 4.2 No Clear Criteria of Data Collection Scope & 0.5243 & 0.1070 & 4 \\
\cline { 2 - 5 } & 4.3 No Clear Criteria of Data Ownership & 0.0486 & 0.0099 & 14 \\
\cline { 2 - 5 } & $\begin{array}{c}4.4 \text { No Clear Leading Actor - the Focal Actor among } \\
\text { Governments }\end{array}$ & 0.1622 & 0.0331 & 10 \\
\hline
\end{tabular}

\section{Discussion and Conclusion}

\subsection{Discussion}

Based on the basic principles of MyData and the STS approach [15] [16] [41] [42] and considering the situation of obstacles to K-MyData, the implications for MyData success were derived as follows.

First, in this study, the biggest obstacle to K-MyData was assessed to be market challenge. In the case of Korea, the K-MyData project is currently carried out as a government initiative. However, the interviewees stated that concerns exist in the market because "there is a fixed time to officially launch the service, but companies are yet to have a certain model" (Interviewee C). Because it is a government-led project, business operators described it as a "situation that they are following because they are worried about business models and profitability, but they are likely to fall behind" (Interviewee L). The Government of Korea also recognizes that the rights to personal data, which are the first basic principle of MyData, do not exist only in a formal manner; they exist as actionable rights [40]. However, the Government has been criticized by civic groups for its concentration on the commercialization of personal information via K-MyData [46]. The government should, therefore, further endeavor to ensure that K-MyData is more faithful to its basic principles and to create a market that will realize it. If the government only emphasizes the need for business related to $\mathrm{K}$ MyData and only drives its implementation, the K-MyData business is likely to fail.

Second, the biggest obstacle among the sub-factors of the market challenge was representative innovative services. The results of the analysis by K-MyData operators (Group 1) and K-MyData supporters (Group 2) were the same. This type of obstacle appears any time a new existing technology is introduced into society, and it can be seen that the same is found in K-MyData [35] [53] [54]. Since K-MyData is a new business model, the emergence of interesting representative services provides opportunities for market growth. This is because consumers can more easily understand the concept of the model, and the market can induce other players to participate and generate profits. Additionally, market challenges with which MyData businesses are not yet familiar are attributed to the lack of "belief in profit and loss." MyData has potential in terms of business and revenue models [7] [11]. However, outstanding innovative services are still required. Government and businesses must once again consider the principle of MyData.

Third, the next biggest obstacle after the market challenge is the institutional challenge. Another principle of MyData, open business environment, can be achieved by putting people at the center. In consideration of these aspects, it is necessary to resolve the institutional challenges. Hence, there is a need to clarify the scope of data collection and the responsibility for accidents. Ambiguous standards for the scope of data collection and unclear roles and responsibility currently block competition under MyData. Therefore, it is necessary for the government to be sensitive to changing this environment while emphasizing the importance 
of the focal actor to lead data industry activation and guarantee the rights of data subjects in a balanced manner [59].

Fourth, socio-cultural issues exist. For the K-MyData business model, data provided by individuals is a core resource. Therefore, in all analyses results, the common "consensus on data provision" appeared at the top. This part is likely to be resolved naturally when the individual is centered, and the authority over one's own data is given, as with the MyData model [1]. It is also crucial that major business participants make efforts to gain consumer trust [34] [41]. Additionally, it is notable that technical barriers have the lowest priority not only in the above category but also in the lower sub-factor analysis results. Furthermore, the comparison results between groups were the same. This is the result of a number of preresearch studies that contradicted the belief that technology is a major obstacle [19] [23] [33]. Although MyData technology is important, MyData businesses must overcome market, sociocultural, and institutional challenges, and they are considered more pressing matters than technology in relation to MyData implementation. The fact that market, socio-cultural, and institutional aspects are bigger obstacles, apart from technology, reinforces the results of extant STS research [20] [21] [41] [42].

\subsection{Conclusion}

This paper identified the challenging factors that hinder the successful settlement of the MyData industry and analyzed the priority of the solution using an ANP technique. To this end, a mixed methodology was adopted to identify variables, analyze them, and interpret the results [14] [38] [39].

This research is likely to contribute to the achievement of a human-centric MyData in terms of business, and it is expected to be a reference point to the governments and markets of international MyData consideration.

The following theoretical implications were garnered. This study began with the problem that there is limited research about MyData principles from consumers vs. businesses perspectives [7] [11]. After subdividing key agents of the business that were overlooked, their positions were presented systematically in terms of MyData principles; thus, this study helps fill this gap. From an STS perspective, it contributes to the study of socio-technical systems perspectives by adding awareness studies of business operators in the field of MyData.

The practical implications are as follows. K-MyData is a government-led model. Hence, it is possible to comprehend implications to countries, such as Korea, where the government intends to prompt the data industry as its focal actor [59]. If the government is well-versed in the basic principles of MyData and understands the difficulties faced by business operators, it is possible to formulate the correct direction of policy. K-MyData has launched only in the financial sector, but the focal actor will be more important in the future because it requires coordination between ministries to expand to public, health, transportation, and other industries (Interviewee B). Hence, if MyData is to expand into national infrastructures and services in the future, it is critical that focal actors create the foundation for the data ecosystem based on balanced MyData principles.

This research examined obstacles to the activation of K-MyData from the business perspective. From the perspective of the MyData models and principles, the business perspective is one axis, and the other is that of the individual data owner [1]. There is limitation to this research in that it did not address the consumers' perspective: it focused on the business perspective. Hence, for the purpose of researching human-centered MyData, it is expected that a follow-up study will be conducted to promote K-MyData from the perspective of consumers. We propose the following specific supplemental studies. For the long-term growth of the 
MyData business, it is important to encourage the active participation of data sovereign individuals. In other words, a culture and environment in which consumers are willing to provide their data should be created. This paper mentions that "lack of consensus on the provision and utilization of data" [36] and, in particular, "lack of incentives that exceed the risk for individuals" may prevent social consensus on the provision of data by individuals [33]. In addition, the major variables of this research, such as "lack of trust in business entities," "low awareness of service," and "fear of privacy infringement," may also be a key factor in obstructing consumers' intent to provide personal data. Hence, based on the discussion in this study, it is necessary to identify factors that hinder consumers' intention to participate in the MyData service in the future, i.e., their intention to provide data. In addition, follow-up studies, such as plans for incentive design of business operators, for building trust, and for the government's policy direction, are required.

\section{Appendix}

Appendix 1. In-depth Interviews for Identifying the Challenges in MyData

\begin{tabular}{|c|c|c|c|}
\hline Field & Code & Specialized Field & Work Period \\
\hline \multirow{3}{*}{$\begin{array}{l}\text { Academics } \\
\qquad(n=3)\end{array}$} & 1 & Academics & 20 years \\
\hline & 2 & Academics & 19 years \\
\hline & 3 & Academics & 21 years \\
\hline \multirow{3}{*}{$\begin{array}{l}\text { Attorney } \\
\qquad(n=3)\end{array}$} & 4 & Attorney & 16 years \\
\hline & 5 & Attorney & 18 years \\
\hline & 6 & Attorney & 20 years \\
\hline \multirow{3}{*}{$\begin{array}{l}\text { Civic Group } \\
\qquad(\mathrm{n}=3)\end{array}$} & 7 & Civic Group & 17 years \\
\hline & 8 & Civic Group & 18 years \\
\hline & 9 & Civic Group & 17 years \\
\hline \multirow{8}{*}{$\begin{array}{l}\text { Industry } \\
\qquad(n=8)\end{array}$} & 10 & Bank & 17 years \\
\hline & 11 & Bank & 15 years \\
\hline & 12 & Bank & 18 years \\
\hline & 13 & Fintech & 17 years \\
\hline & 14 & Fintech & 20 years \\
\hline & 15 & Fintech & 22 years \\
\hline & 16 & Telecom & 23 years \\
\hline & 17 & Telecom & 20 years \\
\hline \multirow{4}{*}{$\begin{array}{l}\text { Government } \\
\qquad(\mathrm{n}=4)\end{array}$} & 18 & Personal Information Protection Committee & 17 years \\
\hline & 19 & Financial Services Commission & 15 years \\
\hline & 20 & Ministry of Science and ICT & 16 years \\
\hline & 21 & Korea Communications Commission & 20 years \\
\hline
\end{tabular}

Appendix 2. The Challenges in Activating MyData

\begin{tabular}{|l|l|}
\hline \multicolumn{1}{|c|}{ Description of Categories \& Challenges } & \multicolumn{2}{c|}{ References } \\
\hline Technical Challenges & \multicolumn{2}{|c|}{} \\
\hline Insufficient API technology for data transmission and receipt standardization (adopted) & $\bullet[10][33]$ [34] [48] \\
\hline Lack of guarantee of data transmission stability (merged) & $\bullet$ [22] [23] [33] [48] \\
\hline Lack of applicability and practicability & [33] \\
\hline
\end{tabular}




\begin{tabular}{|c|c|}
\hline Lack of data storage management technology (adopted) & • $[23][33][49][50]$ \\
\hline Risk of system failure (system failure possibility) & - $[41][49]$ \\
\hline Lack of data quality management technology (adopted) & $\begin{array}{l}\text { - }[41][51][53] \\
\text { - Interviewee } 10\end{array}$ \\
\hline Data security risk (adopted) & - $[23][31][41][54]$ \\
\hline High investment cost & - $[33]$ \\
\hline \multicolumn{2}{|l|}{ Market Challenges } \\
\hline Lack of professionals (data analysts) (adopted) & • $[23][33][35][54]$ \\
\hline Lack of demand (merged) & • $[33]$ \\
\hline No profit model (adopted) & $\begin{array}{l}\text { - }[33][34][41][52] \\
\quad[55]\end{array}$ \\
\hline No Platform governance (platform governance) & - $[52]$ \\
\hline Lack of representative innovative services (adopted) & $\begin{array}{l}\cdot[35][47][54] \\
\cdot \text { Interviewee } 2\end{array}$ \\
\hline Cost related to coordination (merged) & $\cdot[52]$ \\
\hline Lack of management support & • $[33]$ \\
\hline Expansion of co-work players in the market (adopted) & - Interviewee 12 \\
\hline \multicolumn{2}{|l|}{ Socio-cultural Challenges } \\
\hline Lack of consensus on the provision and utilization of data (adopted) & • $[23][31][33]$ \\
\hline Lack of trust in the business entity (adopted) & $\bullet[34][41]$ \\
\hline Fear of privacy infringement (adopted) & - $[23][41]$ \\
\hline Low awareness of services (adopted) & - Interviewee 3 \\
\hline Conflicting objectives and values (merged) & - $[56]$ \\
\hline \multicolumn{2}{|l|}{ Institutional Challenges } \\
\hline Lack of efficient legislation to clarify responsibilities (adopted) & $\begin{array}{l}\cdot[57] \\
\text { - Interviewee } 4\end{array}$ \\
\hline Lack of government incentives and regulation & - $[41]$ \\
\hline Data collection scope scheme (adopted) & $\begin{array}{l}\text { - }[56][57] \\
\text { - Interviewee } 2\end{array}$ \\
\hline Data ownership-related criteria (adopted) & $\begin{array}{l}\text { - }[58] \\
\text { - Interviewee } 4\end{array}$ \\
\hline Absence of a focal actor for core government entities (adopted) & $\begin{array}{l}\text { - }[59] \\
\text { - Interviewee } 12\end{array}$ \\
\hline $\begin{array}{l}\text { Improvement of liability-related acts and subordinate statutes } \\
\text { in the event of a data accident (merged) }\end{array}$ & - $[57]$ \\
\hline
\end{tabular}


Appendix 3. Correlations among the Challenges

\begin{tabular}{|c|c|c|c|c|c|c|c|c|c|c|c|c|c|c|c|c|c|}
\hline & \multicolumn{4}{|c|}{1} & \multicolumn{4}{|c|}{2} & \multicolumn{4}{|c|}{3} & \multicolumn{4}{|c|}{4} \\
\hline & & 1.1 & 1.2 & 1.3 & 1.4 & 2.1 & 2.2 & 2.3 & 2.4 & 3.1 & 3.2 & 3.3 & 3.4 & 4.1 & 4.2 & 4.3 & 4.4 \\
\hline \multirow{4}{*}{1} & 1.1 & & $\checkmark$ & & $\checkmark$ & & & & & & $\checkmark$ & $\checkmark$ & & $\checkmark$ & & & $\checkmark$ \\
\hline & 1.2 & & & $\checkmark$ & $\checkmark$ & & & & & & $\checkmark$ & $\checkmark$ & & $\checkmark$ & & $\checkmark$ & \\
\hline & 1.3 & & & & & $\checkmark$ & $\checkmark$ & & & & & & & & & & \\
\hline & 1.4 & & & & & & & & & & $\checkmark$ & $\checkmark$ & & $\checkmark$ & & & $\checkmark$ \\
\hline \multirow{4}{*}{2} & 2.1 & & & $\checkmark$ & $\checkmark$ & & & $\checkmark$ & $\checkmark$ & & & & & & & & \\
\hline & 2.2 & & $\checkmark$ & $\checkmark$ & & & & $\checkmark$ & $\checkmark$ & & $\checkmark$ & & $\checkmark$ & $\checkmark$ & & & $\checkmark$ \\
\hline & 2.3 & & & & & $\checkmark$ & $\checkmark$ & & $\checkmark$ & $\checkmark$ & $\checkmark$ & & $\checkmark$ & & & & \\
\hline & 2.4 & & & $\checkmark$ & $\checkmark$ & $\checkmark$ & $\checkmark$ & & & $\checkmark$ & & & $\checkmark$ & & & & \\
\hline \multirow{4}{*}{3} & 3.1 & & & & & & & & & & $\checkmark$ & $\checkmark$ & $\checkmark$ & & $\checkmark$ & $\checkmark$ & $\checkmark$ \\
\hline & 3.2 & & & & & & & $\checkmark$ & $\checkmark$ & $\checkmark$ & & $\checkmark$ & $\checkmark$ & $\checkmark$ & & & $\checkmark$ \\
\hline & 3.3 & $\checkmark$ & & & $\checkmark$ & $\checkmark$ & & $\checkmark$ & & $\checkmark$ & $\checkmark$ & & & & & & \\
\hline & 3.4 & & & & & & & $\checkmark$ & $\checkmark$ & $\checkmark$ & $\checkmark$ & & & & & & \\
\hline \multirow{4}{*}{4} & 4.1 & & $\checkmark$ & $\checkmark$ & $\checkmark$ & & & & & $\checkmark$ & $\checkmark$ & & & & $\checkmark$ & & $\checkmark$ \\
\hline & 4.2 & & & & & & $\checkmark$ & $\checkmark$ & & & & & & & & & \\
\hline & 4.3 & & & & & & $\checkmark$ & $\checkmark$ & & & & & & & $\checkmark$ & & $\checkmark$ \\
\hline & 4.4 & $\checkmark$ & & & $\checkmark$ & & $\checkmark$ & $\checkmark$ & $\checkmark$ & $\checkmark$ & & $\checkmark$ & & $\checkmark$ & $\checkmark$ & $\checkmark$ & \\
\hline
\end{tabular}

\section{References}

[1] A. Poikola, K. Kuikkaniemi, O. Kuittinen, H. Honko, A. Knuutila \& V. Lähteenoja, MyData-an Introduction to Human-centric Use of Personal Data, Ministry of Transport and Communications, Finland, 2020. Article(CrossRef Link)

[2] T. Lehtiniemi \& J. Haapoja, "Data Agency at Stake: MyData Activism and Alternative Frames of Equal Participation,” New Media \& Society, Vol.22, No.1, pp.87-104, 2020. Article(CrossRef Link)

[3] T. Lehtiniemi \& M. Ruckenstein, "The Social Imaginaries of Data Activism," Big Data \& Society, Vol.6, No.1, pp.1-12, 2019. Article(CrossRef Link)

[4] S. Milan \& M. Gutierrez, "Technopolitics in the Age of Big Data," Networks, Movements \& Technopolitics in Latin America: Critical Analysis and Current Challenges, Cham: Palgrave Macmillan, pp.95-109, 2018. Article(CrossRef Link)

[5] M. Marina, P. Marisa, C. Max \& S. Anna Berti, "Emerging Models of Data Governance in the Age of Datafication,” Big Data \& Society, Vol.7, No.2, pp.1-15, 2020. Article(CrossRef Link)

[6] H. Paul De, P. Vagelis, M. Gianclaudio, B. Laurent \& S. Ignacio, "The Right to Data Portability in the GDPR: Towards User-centric Interoperability of Digital Services," Computer Law \& Security Review, Vol.34, No.2, pp.193-203, 2018. Article(CrossRef Link)

[7] T.T. Huhtala, M. Pikkarainen \& S. Saraniemi, "Exploring Potential Changes in the Business Model: The Impacts of Using Human-Centered Personal Data as a Resource,” Journal of Business Models, Vol.7, No.2, pp. 53-63, 2019. Article(CrossRef Link)

[8] Korea National Law Information Center, Credit Information Act. Article(CrossRef Link)

[9] T.L. Saaty, The Analytic Network Process., RWS Publications, Pittsburgh, 1996.

[10] H. Kwak, M. Cho \& Y. Choi, MyData, the Beginning of Data Economy: In Financial Industry, Samjong Insight, Samjong KPMG Economic Institute, Vol.68, 2020.

[11] K., Laura, K. Timo, P. Minna \& P. Antti, "Emerging Revenue Models for Personal Data Platform Operators: When Individuals are in Control of Their Data," Journal of Business Models; Aalborg, Vol.6, No.3, pp.79-105, 2018. Article(CrossRef Link)

[12] M. Joan Rodon, "Citizens' Cooperation in the Reuse of Their Personal Data: The Case of Data Cooperatives in Healthcare," in Collaboration in the Digital Age, R. Kai, S. Stefan, \& M. Michaela, Ed. Springer, Cham, 2019, pp.159-185. Article(CrossRef Link) 
[13] P. Minna, K. Timo \& I. Marika, "Seizing the Business Opportunities of MyData Service Delivery Network: Transforming the Business Models for Health Insurance Companies,” Journal of Business Models, Vol.8, No.2, pp.39-56, 2020. Article(CrossRef Link)

[14] F. Almeida, "Strategies to Perform a Mixed Methods Study," European Journal of Education Studies, Vol.5, No.1, pp.137-151, 2018. Article(CrossRef Link)

[15] MyData Global Network, Declaration of MyData Principles, MyData Global Network (before the MyData Global association was established), 2017.

[16] J. Lanford, A. Poikola, W. Janssen, V. Lähteenoja \& M. Rikken, Understanding MyData Operators, MyData Global, 2020.

[17] C. Giuseppe, P. Antonio \& R. Marina, “Open Data and Personal Information: A Smart Disclosure Approach Based on Auth 2.0,” in Proc. of European Conference on e-Government, Kidmore End: 135-XII. Kidmore End: Academic Conferences International Limited, Jun. 2013.

[18] N. Shadbolt, “Midata: Towards a Personal Information Revolution,” in Digital Enlightenment Yearbook 2013: The Value of Personal Data, IOS Press, 2013, pp.202-224.

[19] D. Shin, “A Socio-technical Framework for Internet-of-Things Design: A Human-centered Design for the Internet of Things,"Telematics and Informatics, Vol.31, No.4, pp.519-531, 2014. Article(CrossRef Link)

[20] E.L. Trist \& K. Bamforth, "Some Social and Psychological Consequences of the Long-wall Method of Coal Getting,” Human Relations, Vol.4, pp.3-38, 1951. Article(CrossRef Link)

[21] F. Emery, "Characteristics of Socio-technical Systems,” in the Social Engagement of Social Science, a Tavistock Anthology, Vol.2, T. Eric, M. Hugh and T. Beulah, Ed. Philadelphia: University of Pennsylvania Press, 2016, pp.157-186. Article(CrossRef Link)

[22] O. Trelles, P. Prins, M. Snir \& R. Jansen, “Big Data, but are We Ready?,” Nat Rev Genet, Vol.12, No.3, pp.224, 2011. Article(CrossRef Link)

[23] A. Alharthi, V. Krotov \& M. Bowman, “Addressing Barriers to Big Data,” Business Horizons, Vol.60, No.3, pp.285-292, 2017. Article(CrossRef Link)

[24] J. Johnson, "Big Data+ Big Analytics = Big Opportunity,” Financial Executive, Vol.28, No.6, pp.50-53, 2012. Article(CrossRef Link)

[25] S. Hoffman \& A. Podgurski, "Big Bad Data: Law, Public Health, and Biomedical Databases," Journal of Law, Medicine, and Ethics, Vol.41, No.S1, pp.56-60, 2013. Article(CrossRef Link)

[26] P. Schouten, "Big Data in Health Care: solving provider revenue leakage with advanced analytics," Healthcare Financial Management, Vol.67, No.2, pp.40-42, 2013. Article(CrossRef Link)

[27] H.A.M. Daniel, H.Z. Mohd, Z.Z. Ahmad \& M.M. Afendee, "Vulnerabilities and Security Requirements in Smart Metering Networks," KSII Transactions on Internet and Information Systems, Vol.9, No.4, pp.1493-1515, 2015. Article(CrossRef Link)

[28] A.M, Al-Khouri, "Data Ownership: Who Owns My Data," International Journal of Management \& Information Technology, Vol.2, pp.1-8, 2012. Article(CrossRef Link)

[29] M. Van Rijmenam, Think Bigger: Developing a Successful Big Data Strategy for Your Business, Amacom, New York, 2014.

[30] S. LaValle, E. Lesser, R. Shockley, M.S. Hopkins \& N. Kruschwitz, "Big Data, Analytics, and the Path from Insights to Value,” MIT Sloan Management Review, Vol.52, No.2, pp.21-31, 2011. Article(CrossRef Link)

[31] A. McAfee \& E. Brynjolfsson, “Big Data: The Management Revolution,” Harvard Business Review, Vol.90, No.10, pp.60-68, 2012. Article(CrossRef Link)

[32] E. Curry, “The Big Data Value Chain: Definitions, Concepts, and Theoretical Approaches,” New Horizons for a Data-Driven Economy, J. Cavanillas, E. Curry \& W. Wahlster, Ed. Springer, Cham, pp. 29-37, 2016. Article(CrossRef Link)

[33] T.D. Oesterreich \& F. Teuteberg, "Behind the Scenes: Understanding the Socio-technical Barriers to BIM Adoption through the Theoretical Lens of Information Systems Research,” Technological Forecasting and Social Change, Vol.146, pp.413-431, 2019. Article(CrossRef Link)

[34] M.C. Mukeshimana, Z. Zhao, M. Ahmad \& M. Irfan, "Analysis on Barriers to Biogas Dissemination in Rwanda: AHP Approach,” Renewable Energy, Vol.163, pp.1127-1137, 2021. $\underline{\text { Article(CrossRef Link) }}$ 
[35] A. Keeso, Big Data and Environmental Sustainability: A Conversation Starter, Smith School Working Paper Series, University of Oxford, 2014. Article(CrossRef Link)

[36] F. Malomo \& V. Sena, "Data Intelligence for Local Government? Assessing the Benefits and Barriers to Use of Big Data in the Public Sector,” P\&I Policy \& Internet, Vol.9, No.1, pp.7-27, 2017. Article(CrossRef Link)

[37] M. Sun, F. Zhu \& X. Sun, "Influencing Factors of Construction Professionals' Burnout in China: A Sequential Mixed-method Approach," Engineering, Construction and Architectural Management, Vol.27, No.10, pp.3215-3233, 2020. Article(CrossRef Link)

[38] J.W. Creswell \& V.L.P. Clark, Designing and Conducting Mixed Methods Research (3rd ed.), LA:Sage, 2017.

[39] S. Lander, Mixed Methods: A Short Guide to Applied Mixed Methods Research, Amazon Digital Services, 2019.

[40] A. Bryman, Social Research Methods, New York: Oxford University Press, 2012.

[41] H. Zhang, Z. Tang \& K. Jayakar, “A Socio-technical Analysis of China’s Cybersecurity Policy: Towards Delivering Trusted e-government Services,” Telecommunications Policy, Vol.42, pp.409-420, 2018. Article(CrossRef Link)

[42] H. Kim, D.H. Shin \& D. Lee, "A Socio-technical Analysis of Software Policy in Korea: Towards a Central Role for Building ICT Ecosystems,” Telecommunications Policy, Vol.39, pp.944-956, 2015. Article(CrossRef Link)

[43] S. Bhosale \& D. Rohin, "Multi-criteria Vertical Handoff Decision Algorithm Using Hierarchy Modeling and Additive Weighting in an Integrated WLAN/WiMAX/UMTS Environment- A Case Study," KSII Transactions on Internet and Information Systems, Vol.8, No.1, pp.35-57, 2014. Article(CrossRef Link)

[44] A. Horenbeek \& L. Pintelon, "Development of a Maintenance Performance Measurement Framework- Using the Analytic Network Process for Maintenance Performance Indicator Selection,” Omega, Vol.42, No.1, pp.33-46, January, 2014. Article(CrossRef Link)

[45] Financial Services Commission, K-MyData Operating Guideline, FSC, 2021.

[46] J. Jung, "Problem in Korea’s K-MyData and Consumer right,” Sobijareport, pp.22-23, November 2020.

[47] M. Shukla \& L. Mattar, "Next Generation Smart Sustainable Auditing Systems Using Big Data Analytics: Understanding the Interaction of Critical Barriers," Computers \& Industrial Engineering, Vol.128, pp.1015-1026, 2019. Article(CrossRef Link)

[48] Digital Daily Newspaper, “MyData Business Started to Discuss about Open API Standard,” 2020. Article(CrossRef Link)

[49] R. Luken \& F.V. Rompaey, "Drivers for and Barriers to Environmentally Sound Technology Adoption by Manufacturing Plants in Nine Developing Countries," Journal of Cleaner Production, Vol.16, No.1, pp.S67-S77, 2008. Article(CrossRef Link)

[50] Hankyung Newspaper, “MyData speed War,” 2020. Article(CrossRef Link)

[51] C.L.Philip Chen \& Chun-Yang Zhang, "Data-intensive Applications, Challenges, Techniques and Technologies: A Survey on Big Data,” Information Sciences, Vol.275, pp.314-347, 2014. Article(CrossRef Link)

[52] K. Kapoor, A.Z. Bigdeli, Y.K. Dwivedi, A. Schroeder, A. Beltagui \& T. Baines, “A Sociotechnical View of Platform Ecosystems: Systematic Review and Research Agenda,” Journal of Business Research, Vol.128, pp.94-108. 2021. Article(CrossRef Link)

[53] Money Today News, "Prospects and Challenges of MyData Industry,” 2020. Article(CrossRef Link)

[54] S. Sagiroglu \& C. Sinanc, "Big Data: A Review," in Proc. of Collaboration Technologies and Systems (CTS), pp.42-47, 2013. Article(CrossRef Link)

[55] I. Lee, "Big Data: Dimensions, Evolution, Impacts, and Challenges,” Business Horizons, Vol.60, No.3, pp.293-303, 2017. Article(CrossRef Link)

[56] J.M. Choi \& Y. Jo, “A Study on the Right to Data Portability and MyData Industry,” Economy Regulation and Law, Vol.13, No.2, pp.92-107, 2020. Article(CrossRef Link) 
[57] The Scoop Newspaper, "MyData Conflict, If My Information Could Be Used without My Recognition,” 2020.

[58] Edaily Newspaper, "Does Data have Ownership?,” 2020. Article(CrossRef Link)

[59] M. Callon, Some Elements of a Sociology of Translation: Domestication of the Scallops and the Fishermen of St Brieuc Bay, in J., Law (Eds.), Power, Action and Belief: A New Sociology of Knowledge? Routledge \& Kegan Paul, London, 1986, pp. 196-233.

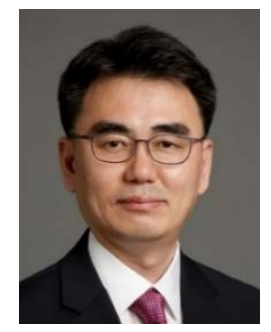

Jeong Kwan Park received BA degree in English literature at Korea University. Then he studied communications policy at City University, London (M.A.) and Westminster University, London (M.A.) respectively. He also studied public policy at KDI International School of Public Policy and Management, Seoul (M.A.). He is currently a doctoral candidate at Yonsei University. He has worked for the Ministry of Science and ICT and the Korea Communications Commission over 20 years and has extensive experiences in the field of ICT policies. He is currently working as a senior consultant at Yulchon LLC.

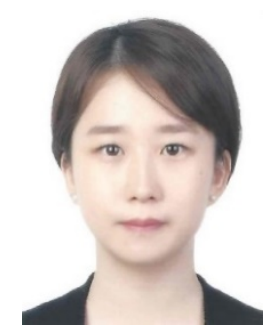

Soo Kyung Park is a Research Professor at Graduate School of Information in Yonsei University. She received her Ph.D. in Business Administration in 2017 from Yonsei University, Korea. Her research interests are in the field of "Management of Technology, "Data Economy," "Platform Business" and "IT Policy." She has published articles in several journals including KSII Transactions on Internet and Information Systems, Internet Research etc.

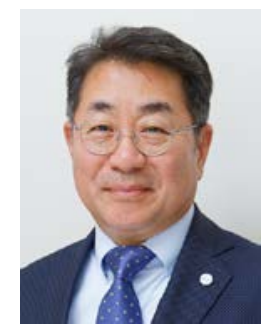

Bong Gyou Lee is a professor at Graduate School of Information in Yonsei University. He also has served as a director of Communications Policy Research Center since 2009. Dr. Lee received a B.A. from the Department of Economics at Yonsei University and he also received his M.S. and Ph.D. from Cornell University. He was a Commissioner of the Korea Communications Commission in 2007 and 2008. 